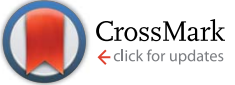

Cite this: RSC Adv., 2017, 7, 13212

\title{
Oxidized single-walled carbon nanotubes and nanocones: a DFT study $\dagger$
}

\author{
Leonardo A. De Souza, ${ }^{a}$ Antônio M. Da Silva Jr, ${ }^{b}$ Hélio F. Dos Santos ${ }^{c}$ \\ and Wagner B. De Almeida*a
}

\begin{abstract}
Carbon nanotubes and nanocones functionalized with polar organic groups can be better dispersed in polar biological fluids, such as the blood stream and, thus, have been considered as promising drug carrier agents. To explore drug-carrying ability and other properties for practical use, molecular modeling can aid the experimental studies by providing the structure and electronic properties of interest for idealized molecular systems. Herein, density functional theory (DFT) was used to investigate molecular features of oxidized carbon nanotube and nanocone models. We evaluated the role of the size of vacancies formed due to the oxidation in the stability of the nanostructures. Raman and IR spectra were collected and assigned for the preferred oxidized models.
\end{abstract}

Received 8th January 2017

Accepted 18th February 2017

DOI: 10.1039/c7ra00301c

rsc.li/rsc-advances generate vacancies or "holes" on the CNT and CNC surfaces and, depending of the oxidative procedure, more severe distortions are observed, such as the removal of carbon atoms such as $\mathrm{CO}$ and $\mathrm{CO}_{2}$. Organic groups like carboxyl, aldehyde, ketone, phenol, alcohol, anhydride and quinone can be formed in the vacancy regions. The defects and groups generated depend on the nature of the oxidizing agent and reaction conditions employed. Kuznetsova et al. ${ }^{18}$ performed experimental studies of the removal of carboxyl and quinone groups from the functionalized carbon nanotubes surface by thermal activation in the temperature range of 623-1073 K. Infrared (IR) spectroscopy was used to confirm the removal of these groups during heating treatment with elimination of $\mathrm{CO}, \mathrm{CO}_{2}, \mathrm{CH}_{4}$ and $\mathrm{H}_{2}$ gases. This removal led to formation of stable opening on the nanotube surface capable of optimizing the Xe gas adsorption at $95 \mathrm{~K}$ inside the nanostructure. The authors showed that the Xe gas adsorption became twenty times greater for the oxidized nanotubes treated at $1073 \mathrm{~K}$ than samples treated at $623 \mathrm{~K}$.

Regarding the mechanism of the oxidation processes, Moon et $a{ }^{19}{ }^{19}$ used first-principles calculations to investigate the oxidation of armchair $(5,5)$ capped CNT by oxygen gas exposure. According to the authors, the gas adsorption in nanotubes with small diameters occurs in the tube cap and wall with an energy barrier of about $2.0 \mathrm{eV}$. On the other hand, the adsorption at the cap is favored in nanotubes with larger diameters, which is the region with highest curvature of the nanostructure. Hamon et $a .^{22}$ experimentally conducted an oxidative reaction of CNT with ${ }^{1} \mathrm{O}_{2}$ generated through photosensitization. The results suggest a cycloaddition mechanism through the atomic oxygen covalent bond to the wall of CNT forming 1,2-dioxetane or a 1,4endoperoxide products. The reaction was monitored and the products characterized by Fourier transform infrared (FT-IR) and ultraviolet/visible/near-infrared (UV-vis-NIR) spectroscopies.
${ }^{a}$ Laboratório de Química Computacional (LQC), Departamento de Química Inorgânica, Instituto de Quimica, Universidade Federal Fluminense, Campus do Valonguinho, Centro, Niterói, RJ 24020-141, Brazil..E-mail: wbdealmeida@gmail.com

${ }^{b}$ Laboratório de Compostos Funcionais Semicondutores (LCFS), Departamento de Química, Instituto de Ciências Exatas, Universidade Federal Rural do Rio de Janeiro - UFRRJ, BR-465, Km 7 Seropédica, Rio de Janeiro, 23.897-000, Brazil

${ }^{c}$ Núcleo de Estudos em Química Computacional (NEQC), Departamento de Química, ICE, Universidade Federal de Juiz de Fora - UFJF, Campus Universitário Martelos, Juiz de Fora, MG, 36.036-330, Brazil

$\dagger$ Electronic supplementary information (ESI) available. See DOI: 10.1039/c7ra00301c 
According to the authors, the reaction is reversible and represents a potentially selective oxidation process in the separation of semiconductor nanotubes from oxidized metallic nanotubes. In the presence of polar solvent, the metallic material is obtained without singlet oxygen under annealing conditions.

The oxidation reaction through the $\mathrm{NO}_{x}(x=1,2,3)$ gases adsorption were studied using DFT calculations by Dai et al. ${ }^{\mathbf{1 6}}$ The authors showed that the chemisorption as a result of bimolecular adsorption of $\mathrm{NO}+\mathrm{NO}, \mathrm{NO}_{3}+\mathrm{NO}_{3}$ and $\mathrm{NO}+\mathrm{NO}_{3}$ species possess strong bonding energy with the CNT surface compared to physical adsorption which occurs when $\mathrm{NO}_{x}$ unimolecular configuration is considered. The adsorption energy is higher in the case of zigzag $(8,0)$ model due its larger curvature effect in relation to the zigzag $(12,0)$ model. The $(12,0) \mathrm{CNT}$ results showed that the process of chemisorption of the $\mathrm{NO}_{3}+\mathrm{NO}_{3}$ system was exothermic, with adsorption energy $-0.75 \mathrm{eV}$, and became endothermic $(+0.5 \mathrm{eV})$ when $\mathrm{NO}_{2}+\mathrm{NO}_{2}$ bimolecular configuration is employed. Recently, Da Silva Jr et al. ${ }^{17 a}$ performed DFT calculations to analyze the structural, electronic, vibrational and energetic properties of the chemical reaction formed between the armchair $(6,6)$ CNT and the acid-base dissociation products of nitric acid. The authors showed that among all the species generated by $\mathrm{HNO}_{3}$ dissociation, the $\mathrm{NO}_{2}{ }^{+}$electrophilic agent is the stronger oxidizer, which transfers oxygen atom to the CNT surface yielding carbonyl groups. A similar study was also conducted by Porto, et al. ${ }^{17 b}$ showing the chemical routes for formation of distinct functional groups, namely ether, epoxide and carbonyl.

In the present study, quantum chemical calculations at DFT level were employed to investigate the structure, electronic and energetic aspects of oxidized carbon nanotubes and nanocones (hereafter called CNTox and CNCox, respectively). The modeling of oxidized topologies is a necessary step towards investigating the relevant properties of advanced materials such as adsorption and releasing of atoms and molecules. The oxidizing topologies were built using as guide the mechanism previously proposed on previous results about the oxidation of carbon nanotubes in the presence of $\mathrm{O}_{2}$ and $\mathrm{H}_{2} \mathrm{O}$ molecules. ${ }^{19,22,32}$ Here we are not focused on the oxidative process shown in Fig. 1, which was described in details in (ref. 32) but on the final fully oxidized structures. Nonetheless, a brief description of the oxidative mechanism is welcome for the readers before discussing the final structures and electronic properties. Initially, a $[2+2]$ type covalent cycloaddition of the $\mathrm{O}_{2}$ molecule is conducted as proposed by Hamon et al. ${ }^{22}$ A reactive organic peroxide is produced, from which a diketone (Fig. 1c) is obtained after breaking the $\mathrm{O}-\mathrm{O}$ and $\mathrm{C}-\mathrm{C}$ (on the nanostructure surface) bonds as shown by Moon et al. ${ }^{19}$ The resonant species of Fig. $1 \mathrm{c}$ in the presence of $\mathrm{O}_{2}$ excess could lead to the formation of compound (d), as well as other oxidized species as describe by Da Silva Jr et $a .^{32}$ Similarly, to the process represented in Fig. 1b and c, an additional step on the nanostructure surface leads to the formation of ketone and lactone groups (Fig. 1e). Lastly, a nucleophilic attack occurs by $\mathrm{H}_{2} \mathrm{O}$ molecule, leading to local formation of the carboxyl group and a hydroxyl linked to carbon atom adjacent to $\mathrm{C}^{*}$ atom (Fig. 1f). Thus, we evaluated the influence of the amount of carboxyl, carbonyl and hydroxyl groups (related with the degree of oxidation) present at the cap and tubular regions of CNTox and CNCox in the (a)

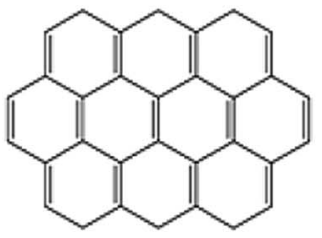

(d)

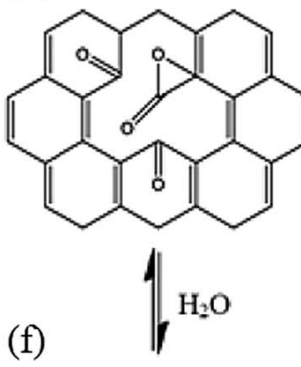

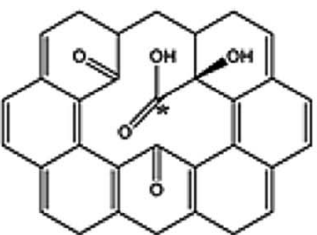

(b)

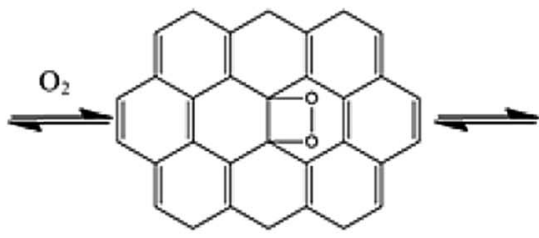

(e)

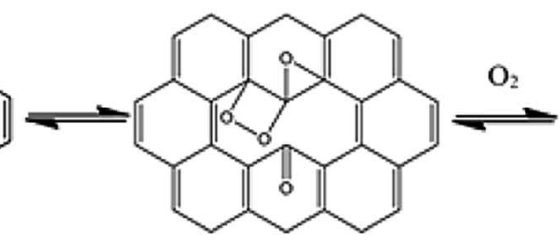

(c)

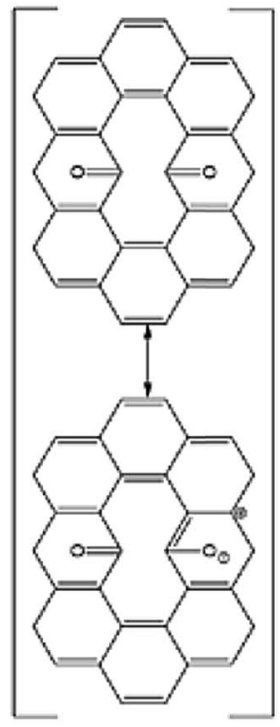

Fig. 1 Oxidative processes proposed in the ref. 32. The entire process is represented as $\mathrm{CN}+2 \mathrm{O}_{2}+\mathrm{H}_{2} \mathrm{O} \rightarrow \mathrm{CNox}$. 
structure-stability relationship. In addition, the infrared (IR) e Raman spectra assignments are presented for the preferred structures based on energy criterion.

\section{Methodology}

Fig. 1 illustrates the oxidation mechanism used to build the CNTox and CNCox models. This mechanism was proposed previously from theoretical studies ${ }^{32}$ for the reaction between an armchair $(5,5) \mathrm{CNT}$ and ${ }^{1} \mathrm{O}_{2}$ and $\mathrm{H}_{2} \mathrm{O}$ molecules. CNTox molecules were built starting from the zigzag $(12,0)$ SWCNT pristine model with one of its extremities closed by hemi-fullerene. CNCox molecules were built starting from the SWCNC pristine model containing four pentagons in its closed end (cone angle equal to $\left.38.9^{\circ}\right){ }^{25}$ The process in Fig. 1 is represented as $\mathrm{CN}+2 \mathrm{O}_{2}+1 \mathrm{H}_{2} \mathrm{O}$ $\rightarrow$ CNox where CNox corresponds to the topology shown in Fig. 1f. This reaction is considered one step of oxidation as illustrated is
Fig. 2. For the CNT, three steps of oxidation were used and for CNC four steps were modelled considering the tubular and cap regions (see details in Fig. 2) being proposed 14 oxidized structures.

The calculations were performed with the Gaussian 09 package $^{33}$ and the geometries fully optimized at the DFT level ${ }^{34}$ with the hybrid B3LYP functional ${ }^{35}$ and the 6-31G basis-set. $^{36}$ The oxidation energy of each step $\left(\Delta E_{\text {oxi }}\right)$ were calculated according to the standard eqn (1):

$$
\Delta E_{\mathrm{oxi}}=E_{\mathrm{Mox}}-\left(E_{\mathrm{PM}}+2 E_{\mathrm{O}_{2}}+E_{\mathrm{H}_{2} \mathrm{O}}\right)
$$

where $E_{\mathrm{Mox}}, E_{\mathrm{PM}}, E_{\mathrm{O}_{2}}$ and $E_{\mathrm{H}_{2} \mathrm{O}}$ stand by the total energy of the oxidized model, pristine model, oxygen and water molecules, respectively. The optimized geometries of CNTox-III and CNCoxIV structures were then used for the vibrational harmonic frequency calculations to derive theoretical vibrational IR and Raman spectra.

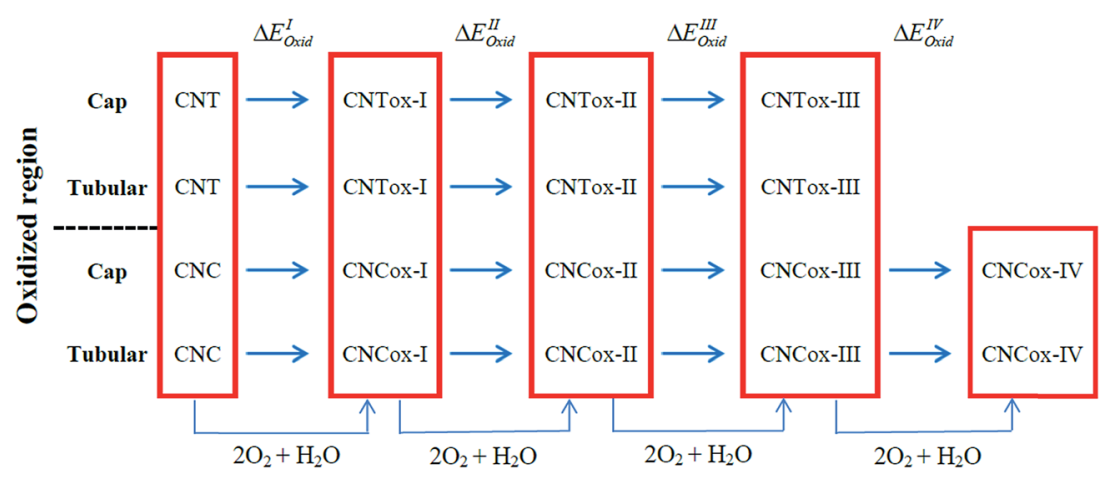

Fig. 2 Oxidation stages calculated in the present study.

(a)

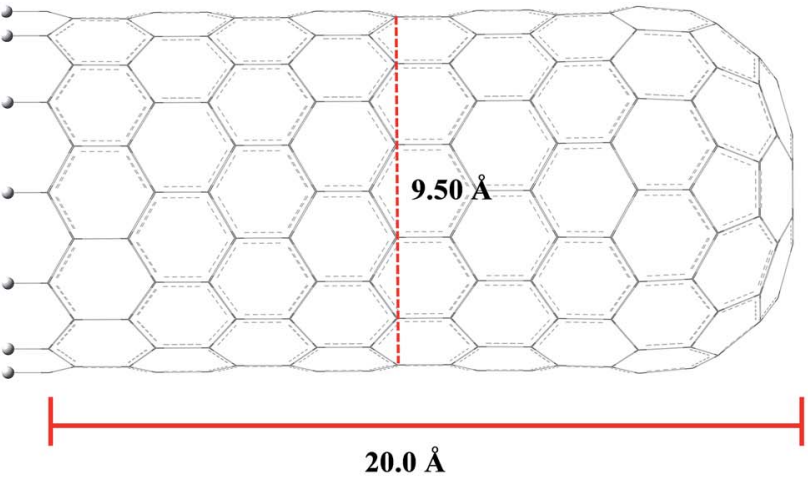

(c)

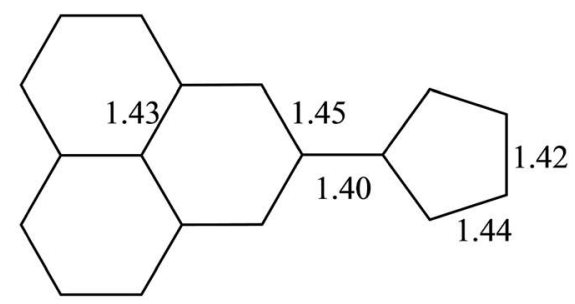

(b)

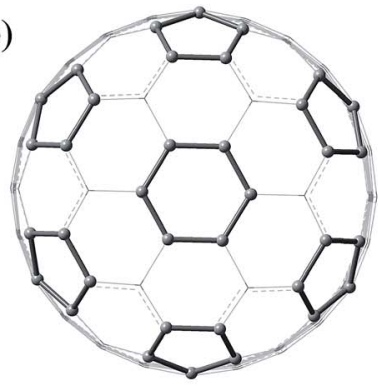

(d)

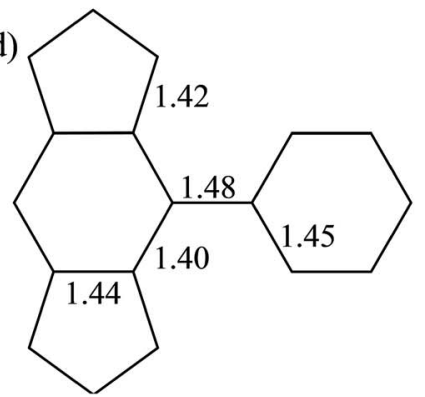

Fig. 3 B3LYP/6-31G optimized structure of zigzag $(12,0)$ CNT (a) and (b) used to build the CNTox models. Figures (c) and (d) represent the main arrangements giving rise to the defect regions (shoulder and cap, respectively). The values shown are the average relative CC bonds in $\AA$. 


\section{Results and discussions}

Fig. 3 and 4 show the pristine $\mathrm{CNT}\left(\mathrm{C}_{240} \mathrm{H}_{12}\right)$ and $\mathrm{CNC}\left(\mathrm{C}_{356} \mathrm{H}_{30}\right)^{25}$ models used to build the oxidized structures, respectively. Hydrogen atoms were added to complete the carbon valence at the open-end (Fig. 3a and 4a). The nanotube has six pentagons with one centered hexagon in the closed-end (Fig. 3b) and the nanocone has four pentagons forming the arrangement shown in Fig. 4b. The CNT optimized geometry at B3LYP/6-31G has nominal length and diameter around 20 and $9.5 \AA$, respectively. The local structure analysis showed that the average CC bond was $1.43 \AA$ for the tubular region and $1.41 \AA$ for the open-rim. Fig. $3 \mathrm{c}$ and d shows the two main arrangements which shape the defect regions (shoulder and-cap, respectively) of the CNT. The values shown represent the average CC bond lengths in the defect region. The bond length found for the pentagonal sites was 1.42-1.44 A. The CC bonds connecting hexagon-pentagon on the shoulder (Fig. 3c) and two hexagons on the cap (Fig. 3d) regions correspond to 1.40 and $1.48 \AA$, respectively. This difference in bond length is due to the greater curvature of the shoulder region, which decreases with the tube diameter. ${ }^{19}$ The CC bonds of the defective region featuring the hexagons not condensate to pentagonal sites (Fig. 3c and d) are slightly longer compared to the tubular region, $\sim 1.45$ A. The CNC B3LYP/6-31G optimized geometry has $21.0 \AA$ length and its average and maximum diameter were calculated about 14.5 and $20.0 \AA$, respectively. The local structure analysis showed that the average CC bond was $1.42 \AA$ for the tubular region (carbon hexagons) with shorter bonds at the open-end, in the range 1.38-1.41 $\AA$. Fig. $4 \mathrm{c}$ and d shows the main arrangements in the defect regions of the CNC. The average bond length found for the pentagonal sites was $1.43 \AA$ A. The CC bonds connecting hexagon-pentagon on the shoulder (Fig. 4c) and two pentagons on the cap (Fig. 4d) regions correspond to 1.38 and $1.37 \AA$, respectively. The $\mathrm{CC}$ bonds of the defective region featuring the hexagons which do not condensate to pentagonal sites (Fig. 4c and d) are slightly longer than in the tubular region (1.43-1.46 ̊).

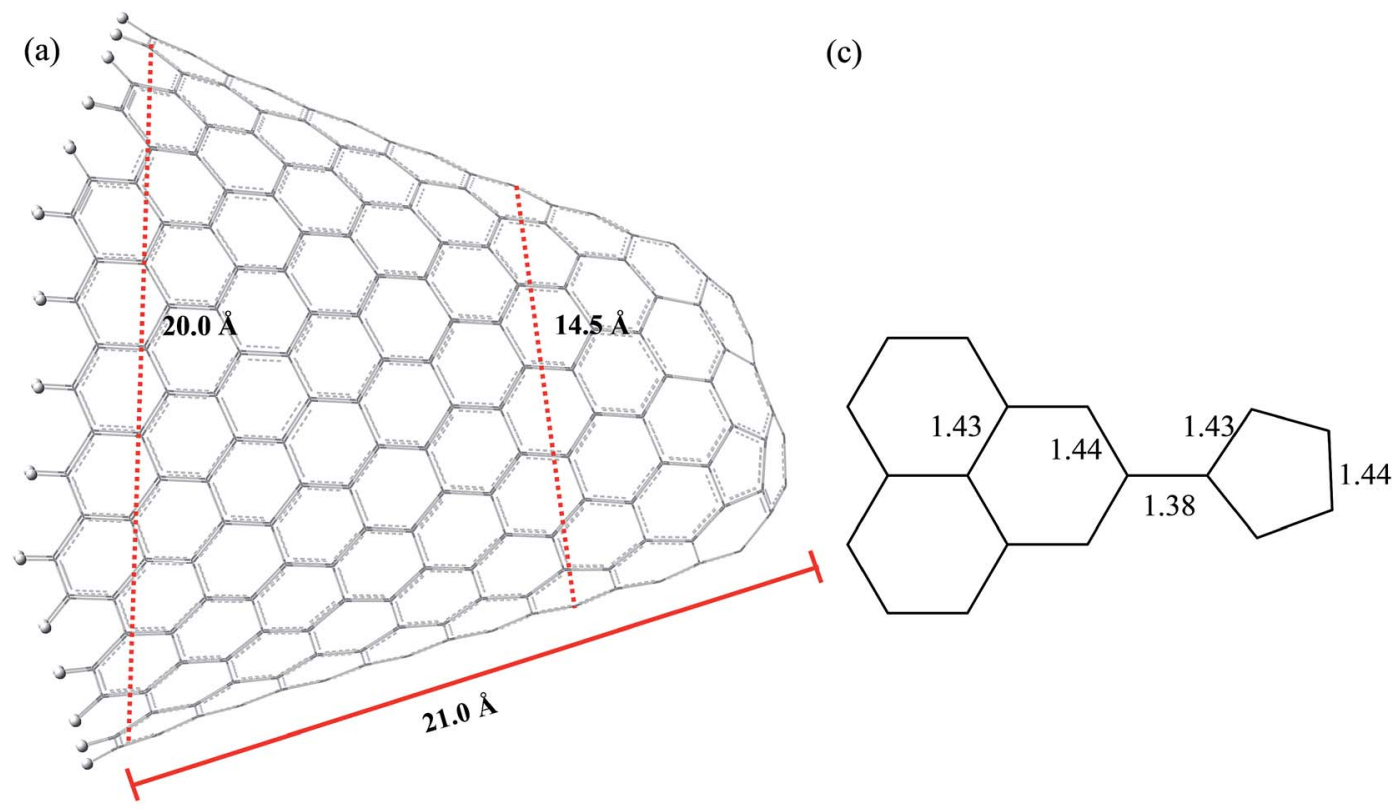

(b)

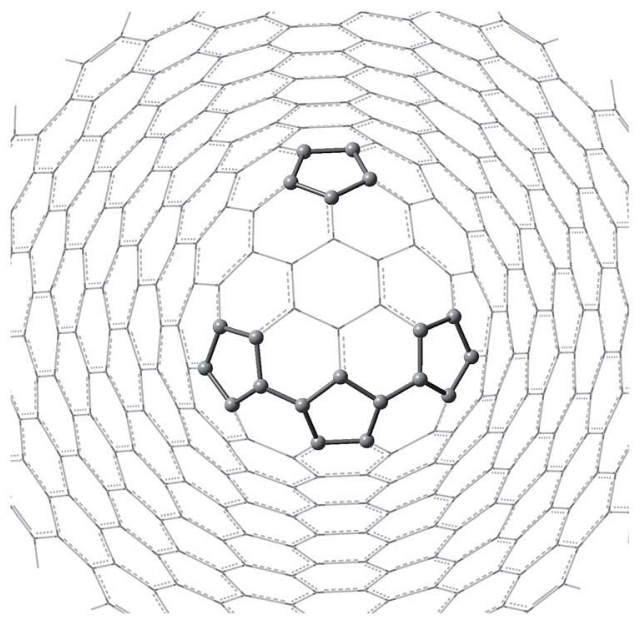

(d)

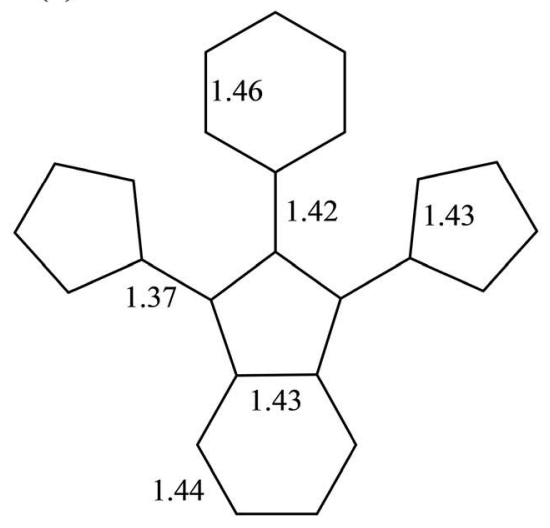

Fig. 4 B3LYP/6-31G optimized structure of CNC (a) and (b) used to build the CNCox models. Figures (c) and (d) represent the main arrangements giving rise to the defect regions (shoulder and cap, respectively). The values shown are the average relative CC bonds in $\AA$. 
The B3LYP/6-31G fully optimized geometries of the CNTox and CNCox models are depicted in Fig. 5 and 6. The left and right columns show the oxidized molecules on the cap and tubular regions, respectively. The molecules are named as CNTox- $n$ and CNCox- $n$, where $n=\mathrm{I}$, II, III or IV indicates the oxidation stages (see Fig. 2). As illustrated in Fig. 1, each oxidation stage refers to the reaction of one mol of $\mathrm{CN}$ with $2: 1$ stoichiometric of $\mathrm{O}_{2}$ and $\mathrm{H}_{2} \mathrm{O}$. Thus, the number of carboxyl, hydroxyl and carbonyl groups increases with the oxidation level. For the stage $n=\mathrm{III}$, for example, we found a total of three carboxyl, three hydroxyl and six carbonyl groups linked to the CNTox-III surface. Following the scheme in Fig. 2, the CNCox-IV model was accomplished starting from the CNCox-III molecule previously optimized and the final structure has a total of four carboxyl, four hydroxyl and eight carbonyl groups linked to the CNCox-IV surface.
From the analysis of the oxidized structures, it is not observed significant changes on the CC bond lengths of the tubular region of oxidized cap CNTox species (Fig. 5a, c and e), found around $1.43 \AA$. On the other hand, due to the increase of organic functional groups on the oxidized tubular region (Fig. 5b and d-f), some CC bonds lengths are shortened and/or elongated in the range of 1.41-1.47 $\AA$. For the CNCox structures, the oxidation of the tubular surface (Fig. $6 \mathrm{~b}, \mathrm{~d}, \mathrm{f}$ and $\mathrm{h}$ ) has great influence in the bond lengths of the carbon hexagonal network of cone tube. The increasing of the number of functional groups on the oxidized tubular region of the CNCox species leads to a shortening or lengthening of the CC bonds in the range 1.41$1.44 \AA$. This effect is less pronounced than that observed for the oxidized CNT (1.41-1.47 ̊), i.e., the CNHox-IV model shows a slightly more rigid structure than CNTox-III model oxidized on the tubular region.

\section{(a)}

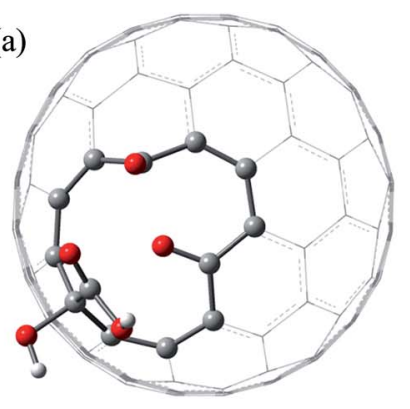

(c)

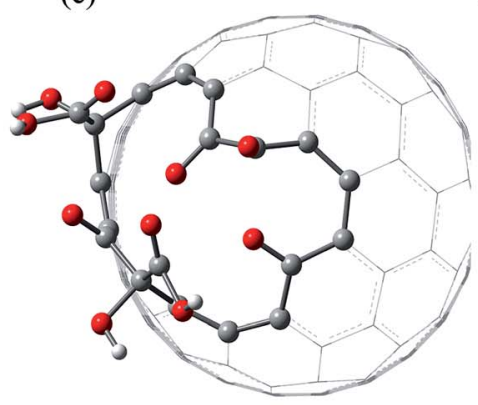

(e)

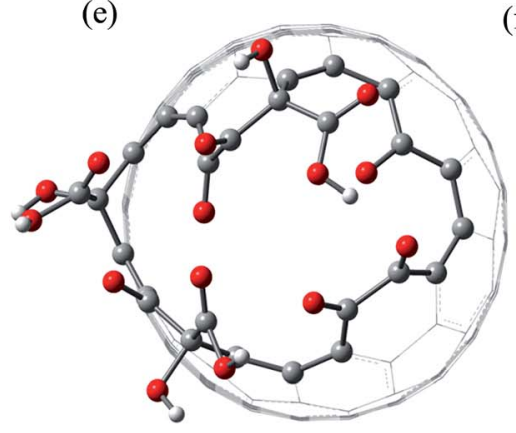

(b)

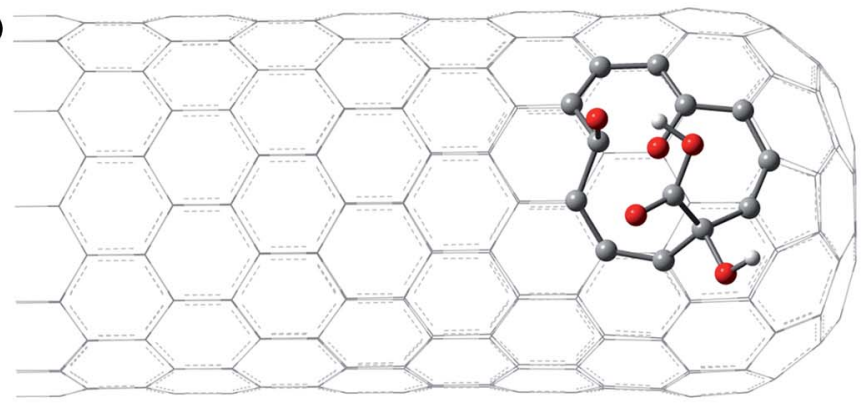

CNTox-I

(d)

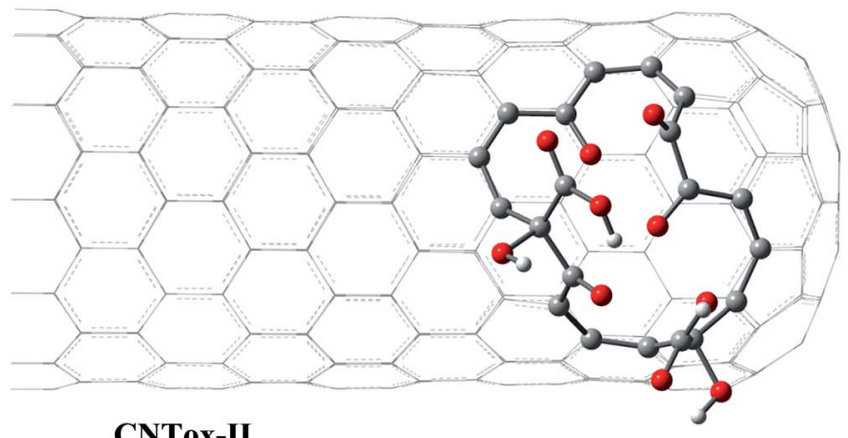

(f)

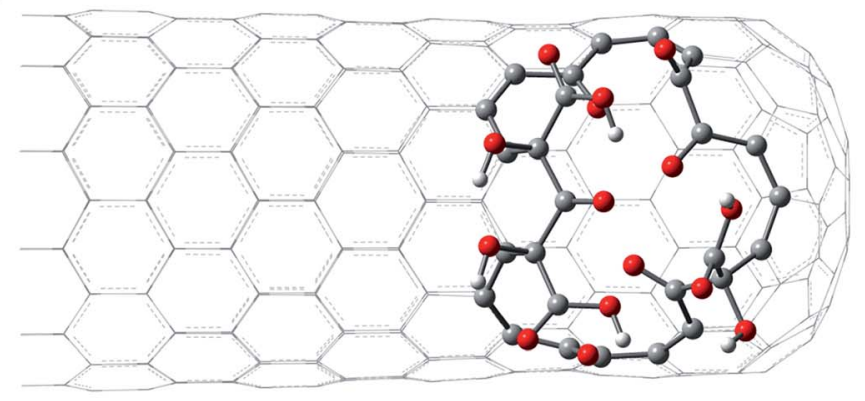

CNTox-III

Fig. 5 B3LYP/6-31G optimized structures of CNTox models. The left and right columns show the oxidized molecules on the cap and tubular regions, respectively. 
We have evaluated the size of vacancies formed through molecular modeling due to consecutive stages employed in the oxidative mechanism. For this purpose, we selected two pairs of carbon atoms that delimit the oxidized surface for each species and a line segment as shown in Fig. 7 and 8 connected the pair of atoms. The changes in the length of the line segments were

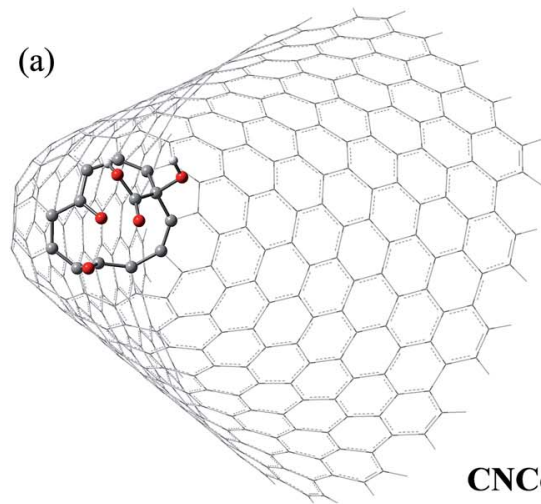

(c)

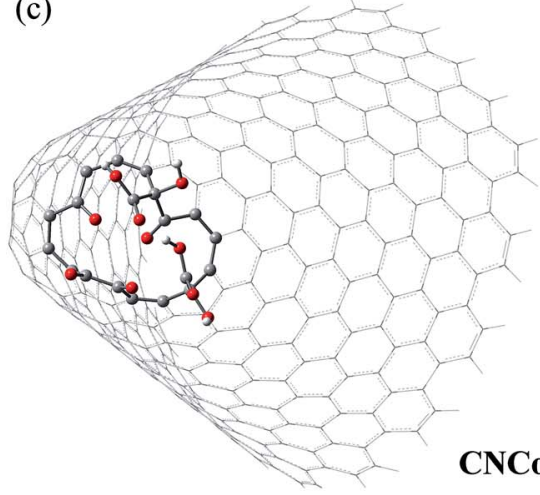

(e)

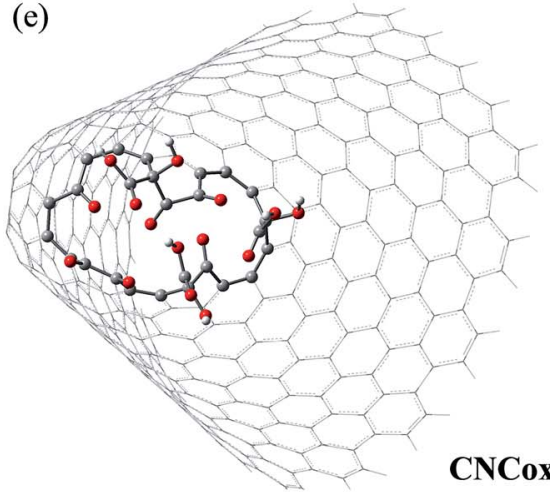

(g)

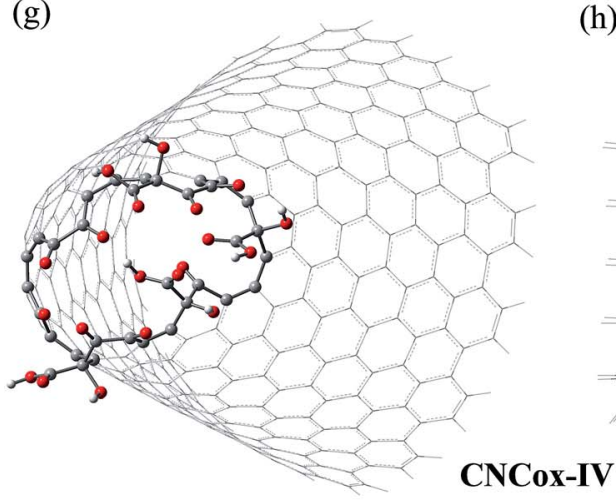

(d)

(f)

(h) (b)
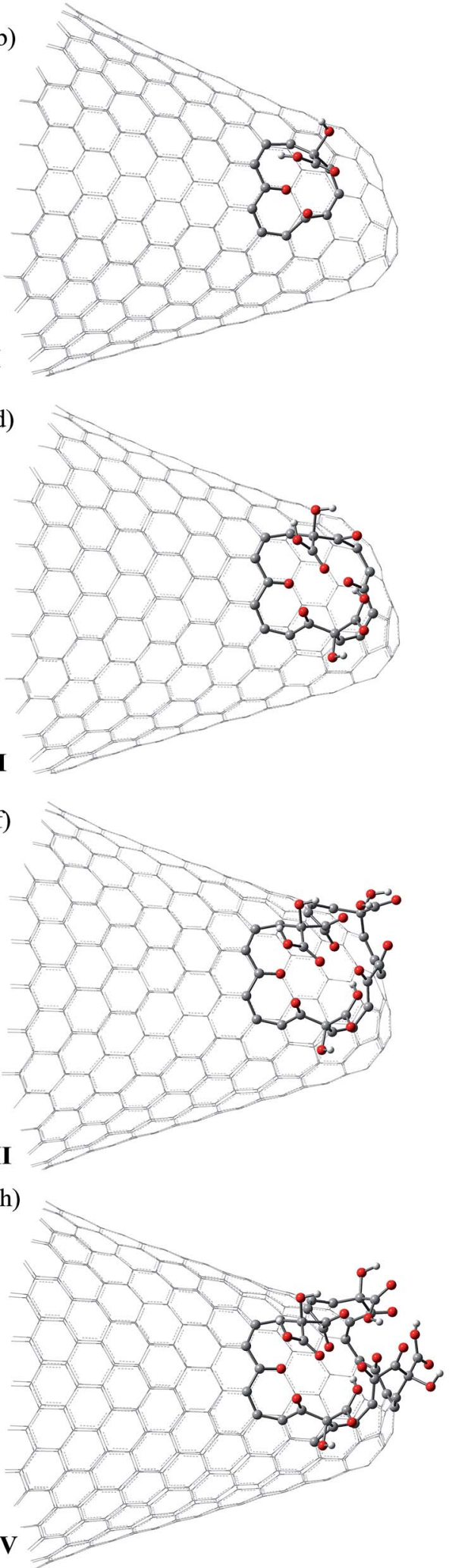

Fig. 6 B3LYP/6-31G fully optimized structures of CNCox models. The left and right columns show the oxidized molecules on the cap and tubular regions, respectively. 
Carbon nanotube

Cap
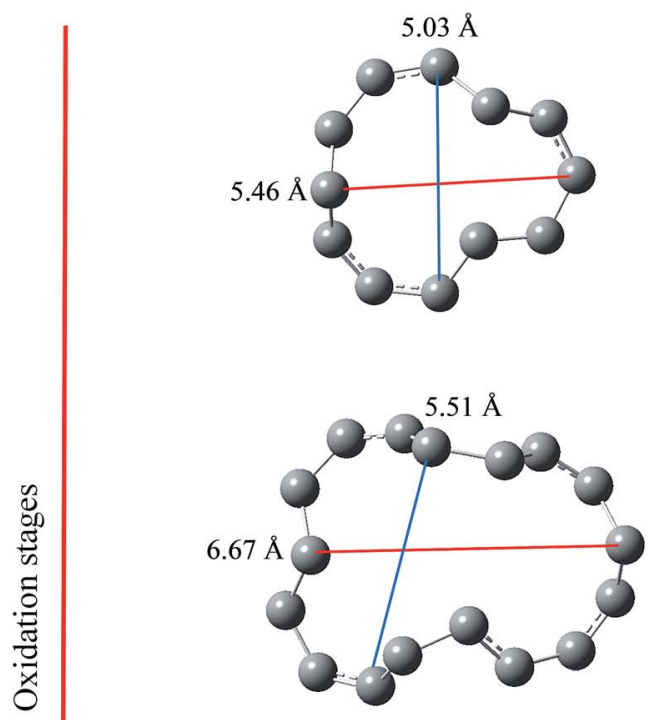

$6.57 \AA$

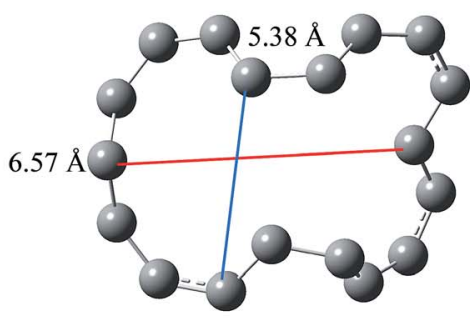

$5.39 \AA$
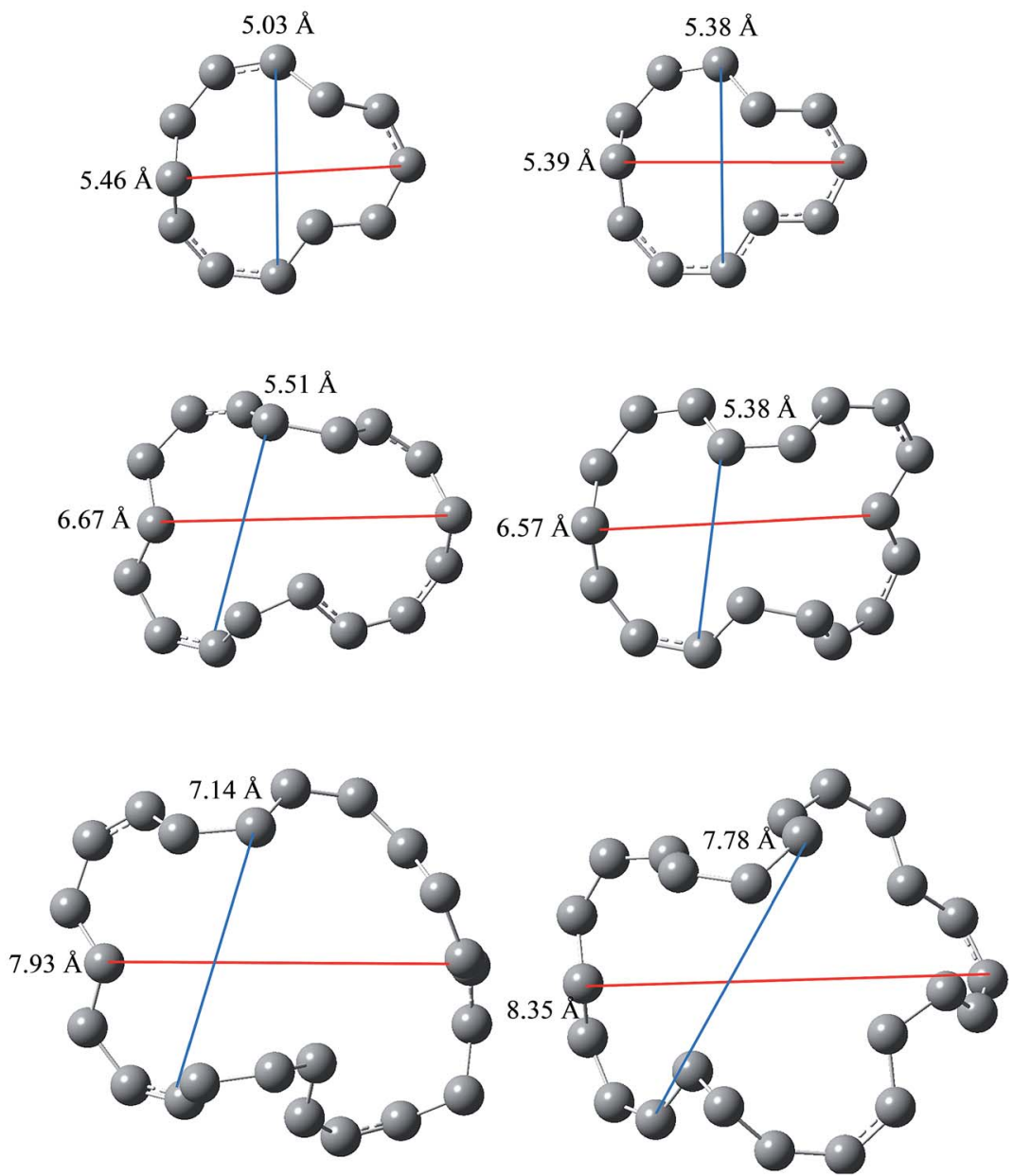

Tube

CNTox-I

(a)

CNTox-II

(b)

CNTox-III

(c)

Fig. 7 Size of the oxidized vacancy with the advance oxidation process for CNT. The distances shown are represented by line segments (red and blue lines) that denote the increase in vacancy generated on the surface of the carbon nanotube.

performed in order to estimate the topological dimension of the oxidized surface area. In general, it was observed that with the progress of oxidation, the size of vacancy increases when we consider the species that belong to the same oxidized region, namely cap or tube. For CNTox models, it was observed an average increase of $2.3 \AA$ and $2.7 \AA$ of the oxidized regions on the cap and tube, respectively, when comparing the models CNTox-I (Fig. 7a) and CNTox-III (Fig. 7c). For CNCox models, it was observed an average increase of $3.7 \AA$ and $4.3 \AA$ of the oxidized regions on the cap and tube, respectively, when comparing the models CNCox-I (Fig. 8a) and CNCox-IV (Fig. 8d). The largest variation on the tubular region is due to the higher surface local area that allows a better rearrangement of the $\mathrm{sp}^{2}$ carbon atoms network. Considering the molecular unit of the cisplatin complex contained in a sphere of approximately $0.5 \mathrm{~nm}$ (the dimensions of cDDP molecule is about $0.4 \mathrm{~nm} \times 0.6 \mathrm{~nm} \times 0.1$ $\mathrm{nm}$ ), it is expected that the drug would pass through the vacancy generated on the oxidized surfaces of the CNTox-III and CNCoxIV nanostructures, despite the oxidized groups that could somehow block the cavities. This feature is an important property to study the controlled release of drugs, like cisplatin which has already been studied by our group..$^{8-10}$

The formation energies $\left(\Delta E_{\text {oxi }}\right)$ of the oxidized models are given in Table 1. It can be seen from values in Table 1 that all reactions are very exothermic. For the first stage, leading to the structures I, the reaction energy at the cap is much lower than at the tubular region, proving that the $\mathrm{CN}$ tips are quite reactive due to the pentagon defects. For CNT, $\Delta E_{\text {oxi }}$ for stage I was (in kcal $\mathrm{mol}^{-1}$ ) -144.5 (cap) and -112.9 (tubular) and for CNC it was -134.5 (cap) and -85.8 (tubular). Our calculations suggest that the CNT is more reactive than CNC during the first stage, which might be due to the smaller average diameter of the former, $9.5 \AA$ and $14.5 \AA$, respectively. Bilu Liu et al. ${ }^{37}$ clearly show from experimental results that single walled carbon nanotubes (SWCNT) of smaller diameters are more reactive in air at high temperatures. The authors also demonstrate that the reactivity of these nanostructures does not depend exclusively on a single structural parameter, but depends on the 
Carbon nanocone

Cap

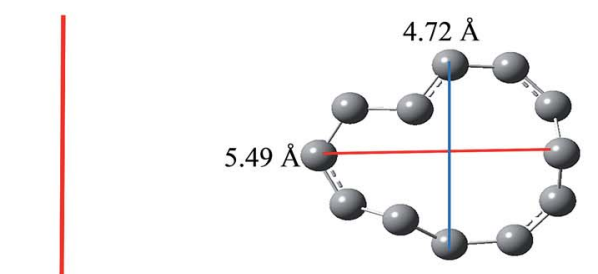

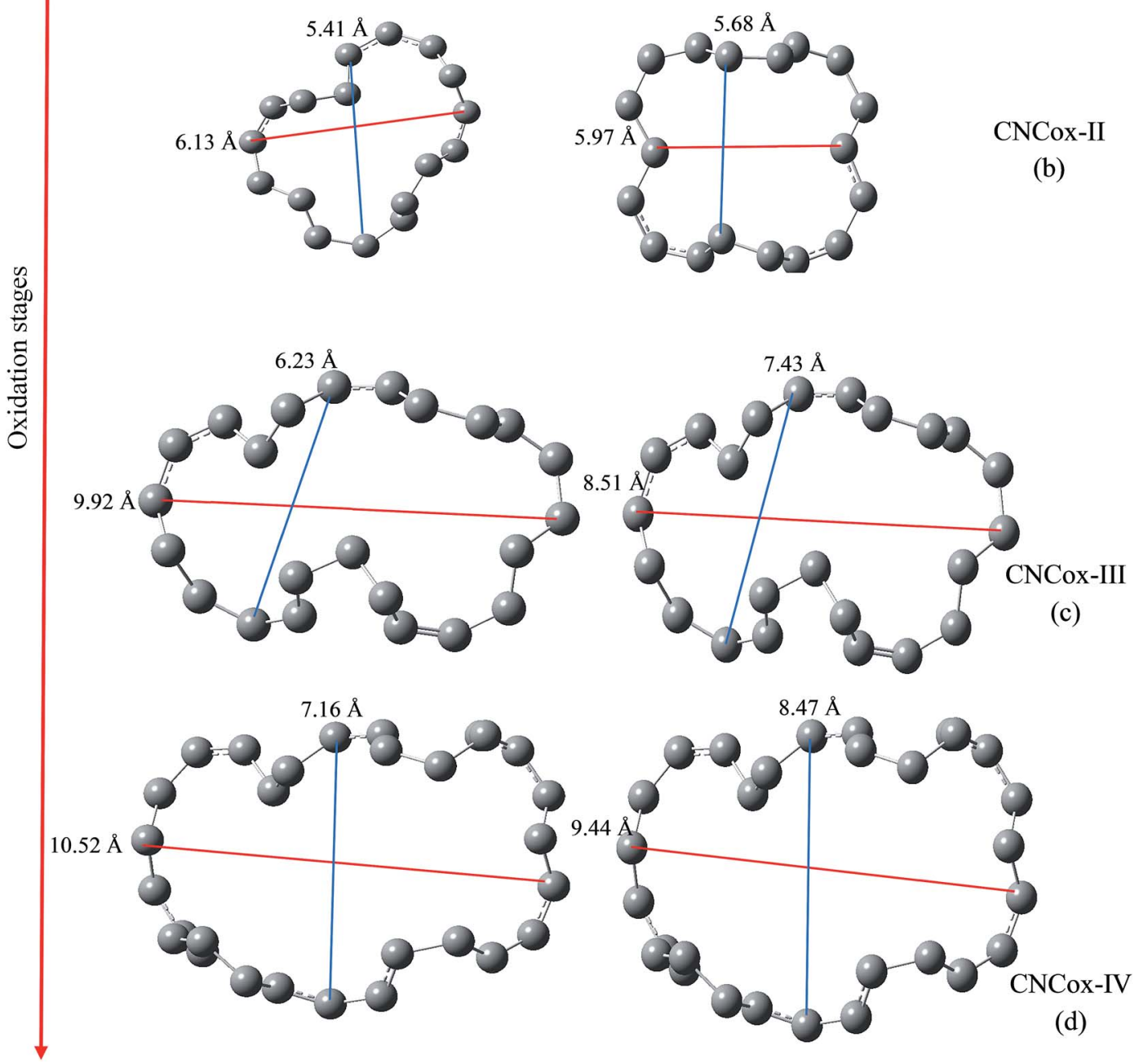

Tube

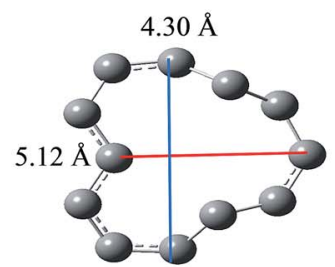

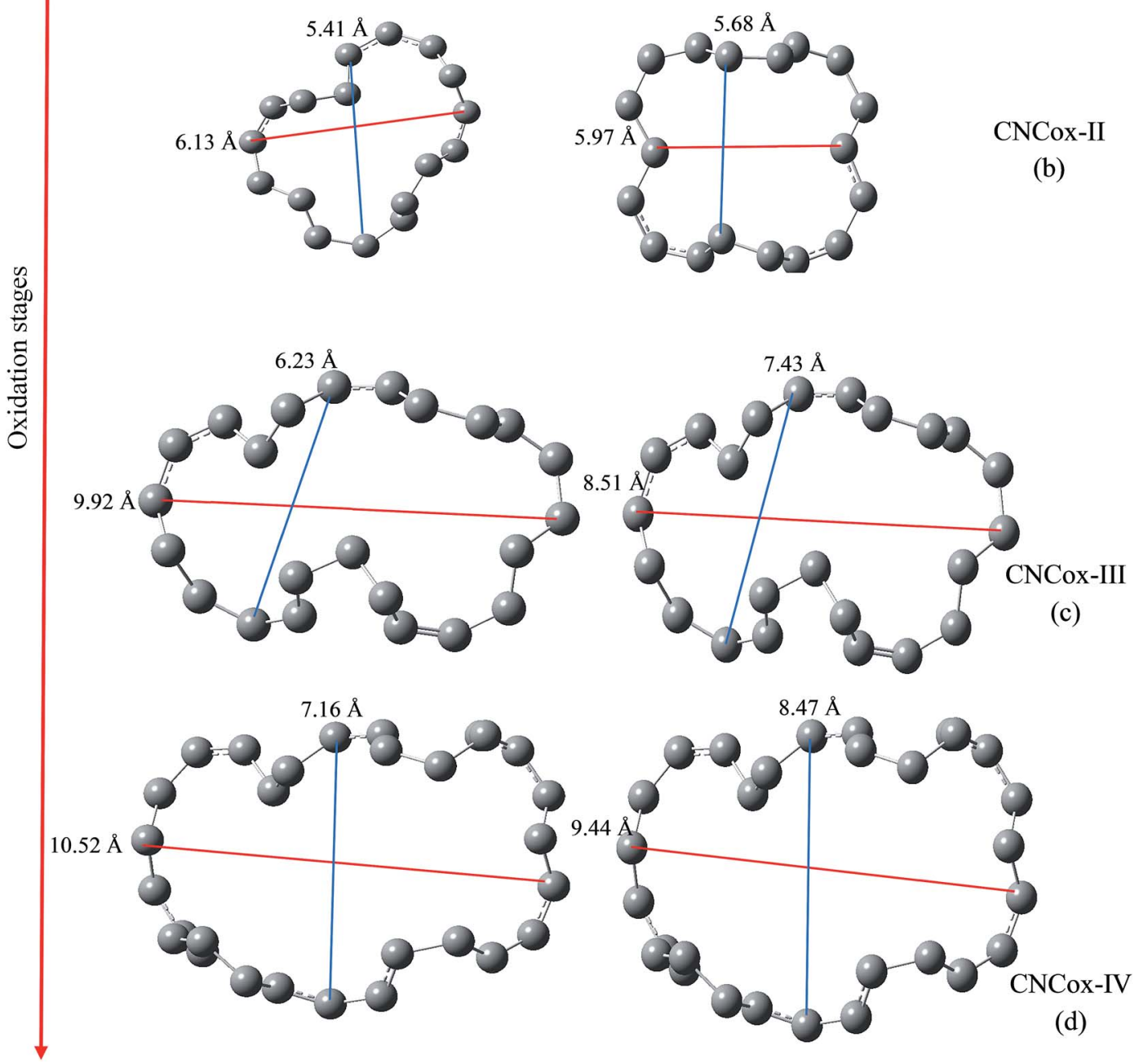

CNCox-I

(a)

Fig. 8 Size of the oxidized vacancy with the advance oxidation process for CNC. The distances shown are represented by line segments (red and blue lines) that denote the increase in vacancy generated on the surface of the carbon nanocone.

relationship between diameter, chirality and chiral angles. Overall, the following oxidation steps are more favorable that the first one, with reaction energy converging to a limit value around $-200 \mathrm{kcal} \mathrm{mol}^{-1}$, regardless the type of $\mathrm{CN}$ and molecular region, even though, the continuing oxidation of the $\mathrm{CN}$ cap is more favorable than the $\mathrm{CN}$ tubular moiety. ${ }^{18,19}$ The cap oxidation decreases the $\mathrm{C}-\mathrm{C}$ bonds stress that define the pentagonal arrangements in this region. Such a decrease of structural stress occurs also on the tube-oxidized species; however, this effect is dependent on further specific structural variations. Therefore, we observed a limit of structural relaxation during the geometry optimization of the final models oxidized, in which a larger number of organic groups are present. Thus, the models become more rigid and are less sensitive to structural stress of defect sites. This explains the small average difference $(\sim 0.75 \AA)$ of the vacancies formed by 
Table 1 Formation energy ( $\Delta E_{\text {oxi }}$ ) of CNTox and CNCox models. All values in units of $\mathrm{kcal} \mathrm{mol}^{-1}$

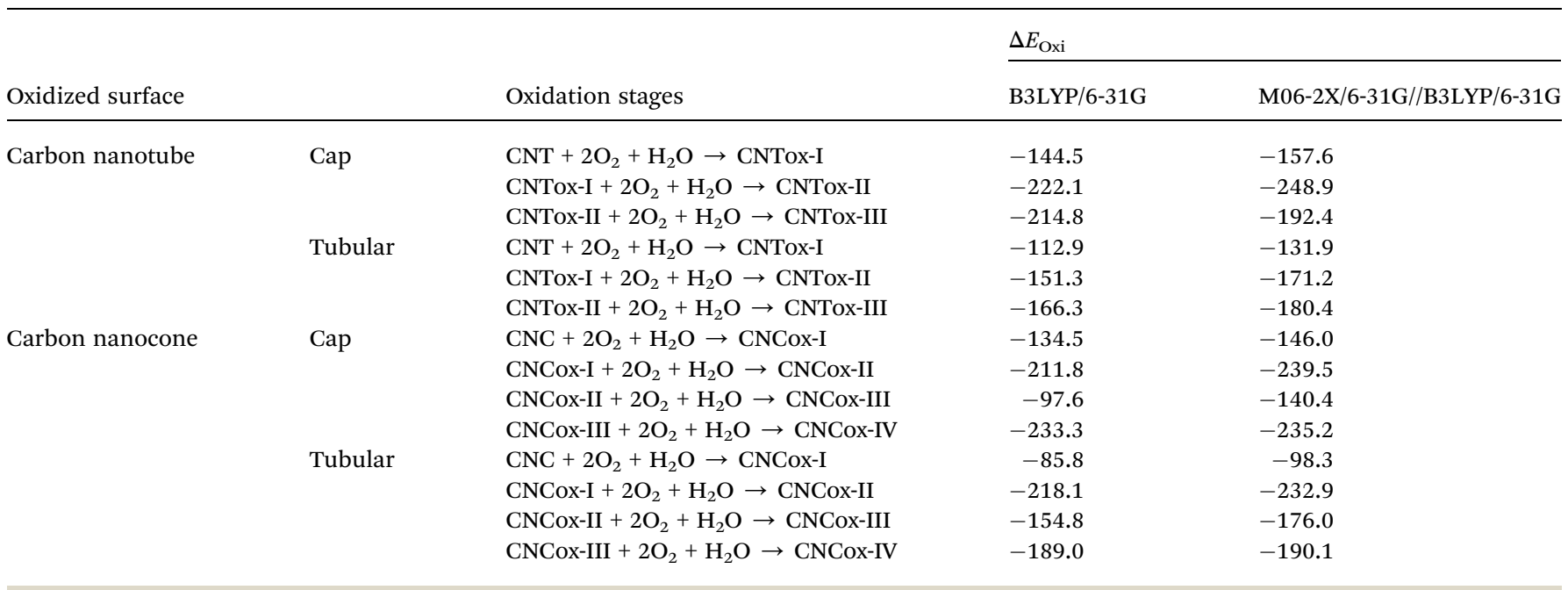

oxidized cap (Fig. 8c and d) between CNCox-III and CNCox-IV models. In ref. 8 we show that the M06-2 $\mathrm{x}^{39}$ functional showed a best performance for describing the electronic correlation and dispersion effects for a model corannulene-cisplatin complex. Thus, we used the DFT M06-2x/6-31G(d,p) level for the prediction of the formation energy of cisplatin-nanocone inclusion complex and also an adsorption complex, using B3LYP/3-21G fully optimized geometries to save computer time. This result motivated us to use in the present work the M06-2x/6-31G level using B3LYP/6-31G fully optimized geometries of oxidized nanostructures proposed. It can be seen from values in Table 1 that the formation energies of the oxidized nanostructures are even more favorable than the corresponding energies calculated at B3LYP/6-31G level. Among the structures of the last oxidation stage the difference observed (in $\mathrm{kcal} \mathrm{mol}^{-1}$ ) is larger for the stage III where the CNTox-III structure is formed, $\sim-22.4$ and -14.1 for oxidized cap and tubular regions, respectively.

The infrared spectrum is not commonly used for characterization of carbon nanostructures due to the high symmetry of the molecules, which results in low intensity transitions. Thus, Raman spectroscopy is frequently preferable. ${ }^{32,38}$ However, when the molecule is functionalized or has a defect region, for example, in the production and/or oxidative process, most of CC and generated organic groups vibrational modes become IR active and might aid to elucidate the overall geometries and local defects. In one of our previous work, ${ }^{25}$ the DFTB calculation results for the IR spectra of the distinct CNCs structures showed that the presence of pentagon-pentagon links (carbon pentagon rings) on the cap surface can be identified by the presence of absorption bands at about $1820 \mathrm{~cm}^{-1}$. Three regions of the CNT and CNC Raman spectrum are commonly used to characterize the disturbance due to their functionalization. Region I (100-300 $\mathrm{cm}^{-1}$ ) presents the RBM mode, which is inversely related to the tube diameter and represents carbon atoms movement in the radial direction; region II (1300-1500 $\mathrm{cm}^{-1}$ ) represents disorder peaks, called D band and region III $\left(1500-1600 \mathrm{~cm}^{-1}\right)$ is assigned to the graphitic $\mathrm{G}$ band. Recently, we described an integrated experimental and theoretical anal$\mathrm{ysis}^{10}$ on the synthesis and characterization of cisplatin/SWCNT inclusion complex. It was observed, that the inclusion of drug

Table 2 B3LYP/3-21G vibrational frequencies (in $\mathrm{cm}^{-1}$ ) and Raman-IR assignments for the pristine carbon nanostructures (CNT and CNC), CNTox-III and CNCox-IV oxidized models. The stretching $(\nu)$ and inplane deformation $(\delta)$ modes are assigned ${ }^{a}$

\begin{tabular}{|c|c|c|}
\hline Structure & Raman assignments & IR assignments \\
\hline CNT & $\begin{array}{l}\text { 183-281 (RBM), } \\
1316 \text { (D), } 1576 \text { (G) }\end{array}$ & $\begin{array}{l}3200\left(\nu_{\mathrm{C}-\mathrm{H}}\right) \text { open edge } \\
1527 \text { and } 1500\left(\delta_{\mathrm{C} 5-\mathrm{C} 6}\right) \\
1415\left(\nu_{\mathrm{C} 5-\mathrm{C} 6}\right)\end{array}$ \\
\hline CNTox-III & $\begin{array}{l}\text { 173-266 (RBM), } \\
1336 \text { (D), } 1575(\mathrm{G})\end{array}$ & $\begin{array}{l}3419\left(\nu_{\mathrm{O}-\mathrm{H}}\right) \text { isolated hydroxyls } \\
3405,3310 \text { and } 3223\left(\nu_{\mathrm{O}-\mathrm{H}}\right) \\
\text { carboxyl group } \\
3201-3191\left(\nu_{\mathrm{C}-\mathrm{H}}\right) \text { open edge } \\
1829,1798 \text { and } 1775\left(\nu_{\mathrm{C}=\mathrm{O}}\right) \\
\text { carboxyl group } \\
1707-1678\left(\nu_{\mathrm{C}=\mathrm{O}}\right) \\
\text { vicinal carbonyls } \\
1195 \text { and } 1130\left(\delta_{\mathrm{C}-\mathrm{OH}}\right) \\
\text { carboxyl group } \\
980,963 \text { and } 936\left(\delta_{\mathrm{sp}^{3}-\mathrm{C}}\right)\end{array}$ \\
\hline $\mathrm{CNC}$ & $\begin{array}{l}\text { 191-224 (RBM), } \\
1367 \text { (D), } 1594(\mathrm{G})\end{array}$ & $\begin{array}{l}3189\left(\nu_{\mathrm{C}-\mathrm{H}}\right) \text { open edge } \\
1677\left(\nu_{\mathrm{C} 5-\mathrm{C} 5}\right) \\
1490 \text { and } 1427\left(\nu_{\mathrm{C} 5-\mathrm{C} 6}\right)\end{array}$ \\
\hline CNCox-IV & $\begin{array}{l}\text { 193-203 (RBM), } \\
1360(\mathrm{D}), 1593(\mathrm{G})\end{array}$ & $\begin{array}{l}3415-3363\left(\nu_{\mathrm{O}-\mathrm{H}}\right) \\
\text { isolated hydroxyls } \\
3408,3291 \text { and } 3034\left(\nu_{\mathrm{O}-\mathrm{H}}\right) \\
\text { carboxyl group } \\
3239-3191\left(\nu_{\mathrm{C}-\mathrm{H}}\right) \text { open edge } \\
1851,1664 \text { and } 1637\left(\nu_{\mathrm{C}=\mathrm{O}}\right) \\
\text { carboxyl group } \\
1682,1670,1655,1546\left(\nu_{\mathrm{C}=\mathrm{O}}\right) \\
\text { vicinal carbonyls } \\
1209,1170 \text { and } 1150\left(\delta_{\mathrm{C}-\mathrm{OH}}\right) \\
\text { carboxyl group } \\
1110,1075,962 \text { and } 935\left(\delta_{\left.\mathrm{Sp}^{3}-\mathrm{C}\right)}\right.\end{array}$ \\
\hline
\end{tabular}


into the nanotube affects the $\mathrm{G}$ and $\mathrm{D}$ bands intensity, suggesting an increase of structural disorder. Moreover, a decrease was observed of the wavenumber in the spectral range of the radial breathing modes (RBM) by $9 \mathrm{~cm}^{-1}$ with the nanotube functionalization with the cisplatin molecules. The Raman and IR main transitions and assignments for the CNTox-III and CNCox-IV oxidized models, as well as, CNT and CNC pristine models are summarized in Table 2. As a general observation, the intensity of the RBM mode decreases with insertion of the organic groups and the transitions are observed in the range of 180 to $280 \mathrm{~cm}^{-1}$. In comparison to the pristine starting models, the oxidized derivatives exhibit a pronounced decrease of the value $G / D$ intensity ratio, an indicative that the covalently bonded organic groups on the cap increase the structural disorder. Our results show that the G/D value decreased from 9.5 (pristine CNT) to 0.6 (CNTox-III model) and from 1.5 (pristine CNC) to 0.4 (CNCox-IV). Fig. S1 and S2 (ESI $\dagger$ ) promptly allow the identification of fingerprints bands. The IR spectrum calculated to pristine models revealed absorption band close to $1415 \mathrm{~cm}^{-1}$ (CNT) and in the range of 1427-1490 $\mathrm{cm}^{-1}$ (CNC) assigned to pentagon-hexagon (C5-C6) links CC stretching $(\nu)$ on the cap. These bands are not observed in the oxidized forms. One absorption band close to $3185 \mathrm{~cm}^{-1}$, regardless of the pristine model, is assigned to $\mathrm{CH}$ stretching of the edges. Regarding the oxidized models, the absorption bands in the range of $900-1110 \mathrm{~cm}^{-1}$ are assigned to generated $\mathrm{sp}^{3}$ carbon atoms angular deformations $(\delta)$ as defects in the $\mathrm{sp}^{2}$ carbon network. The main transitions related to organic groups can be assigned as: (i) slightly more intense bands at frequencies higher in the range $3200-3420 \mathrm{~cm}^{-1}$ due to hydroxyls stretching of carboxyls (about at $3200 \mathrm{~cm}^{-1}$ ) and isolated hydroxyls (at $3360-3420 \mathrm{~cm}^{-1}$ ); (ii) intense transitions in the range of 1750$1850 \mathrm{~cm}^{-1}$ related to carbonyl stretching of carboxyl; (iii) absorption bands in the range of $1545-1710 \mathrm{~cm}^{-1}$ indicate vicinal carbonyls stretching. Through our results, we claim that the present study might assist the experimentalist in the structural characterization of this highly complex class of molecules, providing molecular models for other theoretical studies of oxidized carbon nanostructures.

\section{Conclusions}

In this paper, the DFT method was used to modeling oxidized carbon nanotube (CNTox) and nanocone (CNCox) topologies. Our calculations demonstrated that the sequential insertion of carbonyl, hydroxyl and carboxyl groups increase the vacancies size on the tube and cap regions of carbon nanostructures. Moreover, the cap oxidation decreases the CC bond stress of the pentagonal arrangements, thus, the formation of the CNTox and CNCox species oxidized on the cap are more favorable than on the tubular region. Raman spectra show that the G/D intensity ratio exhibit a pronounced decrease upon oxidation, mainly for CNT species (9.5 to 0.6), indicating that the covalent functionalization of the nanostructure surface increased the structural disorder. IR spectra were calculated, and an attempt assignment was made to identify the organic groups present. The introduction of carbonyl, hydroxyl and carboxyl groups may be used for the connection of functional entities, increase the dispersion of nanostructures in more polar environments and form more readily available nanocomposites for delivery and controlled release of drugs.

\section{Acknowledgements}

The authors would like to thank the Brazilian Agencies CNPq, CAPES and FAPEMIG for providing support to this study. L. A. De Souza thanks the CAPES for a Post-Doctoral scholarship. HFDS also thank FAPEMIG (APQ-00591-15).

\section{References}

1 H. J. Jung, Y.-J. Kim, J. H. Han, M. Yudasaka, S. Iijima, H. Kanoh, Y. H. Kim, K. Kaneko and C.-M. Yang, J. Phys. Chem. C, 2013, 117, 25877-25883.

2 R. Yuge, J. Miyawaki, T. Ichihashi, S. Kuroshima, T. Yoshitake, T. Ohkawa, Y. Aoki, S. Iijima and M. Yudasaka, ACS Nano, 2010, 4, 7337-7343.

3 A. De Luca, M. Cole, R. Hopper, S. Boual, J. Warner, A. Robertson, S. Ali, F. Udrea, F. Gardner and W. Milne, Appl. Phys. Lett., 2015, 106, 1-5.

4 U. N. Maiti, W. J. Lee, J. M. Lee, Y. Oh, J. Y. Kim, J. E. Kim, J. Shim, T. H. Han and S. O. Kim, Adv. Mater., 2014, 26, 40-67.

5 H. A. Shaheen, H. M. Marwani and E. M. Soliman, J. Mol. Liq., 2015, 212, 480-486.

6 P. Sahoo, R. G. Shrestha, L. K. Shrestha, J. P. Hill, T. Takei and K. Ariga, J. Inorg. Organomet. Polym., 2016, 1574, 14431451.

7 A. Guven, I. A. Rusakova, M. T. Lewis and L. J. Wilson, Biomaterials, 2012, 33, 1455-1461.

8 L. A. De Souza, C. A. S. Nogueira, J. F. Lopes, H. F. Dos Santos and W. B. De Almeida, J. Inorg. Biochem., 2013, 129, 71-83.

9 L. A. De Souza, C. A. S. Nogueira, J. F. Lopes, H. F. Dos Santos and W. B. De Almeida, J. Phys. Chem. C, 2015, 119, 83948401.

10 L. A. De Souza, C. A. S. Nogueira, P. F. R. Ortega, J. F. Lopes, H. D. R. Calado, R. L. Lavall, G. G. Silva, H. F. Dos Santos and W. B. De Almeida, Inorg. Chim. Acta, 2016, 447, 38-44.

11 R.-T. Zeng, W. Hu, M. Wang, S.-D. Zhang and J.-B. Zeng, Polym. Test., 2016, 50, 182-190.

12 L. A. De Souza, A. M. Da Silva Jr, G. M. A. Junqueiraa, A. C. M. Carvalho and H. F. Dos Santos, J. Mol. Struct., 2010, 959, 92-100.

13 A. M. Da Silva Jr, G. M. A. Junqueira, H. F. Dos Santos and A. C. M. Carvalho, Quim. Nova, 2009, 32, 315-321.

14 A. E. A. Machado, L. A. De Souza, H. F. Dos Santos and W. B. De Almeida, J. Polym. Sci., Part B: Polym. Phys., 2011, 49, 1410-1419.

15 L. Sun, C. Wang, Y. Zhou, X. Zhang, B. Cai and J. Qiu, Appl. Surf. Sci., 2013, 277, 88-93.

16 J. Dai, P. Giannozzi and J. Yuan, Surf. Sci., 2009, 603, 32343238.

17 (a) A. M. Da Silva Jr, H. F. Dos Santos and P. Giannozzi, Chem. Phys. Lett., 2013, 582, 123-128; (b) A. B. Porto, 
L. F. C. Oliveira and H. F. Dos Santos, Comput. Theor. Chem., 2016, 1088, 1-8.

18 A. Kuznetsova, D. B. Mawhinney, V. Naumenko, J. T. Yates, J. Liu and R. E. Smalley, Chem. Phys. Lett., 2000, 321, 292296.

19 C.-Y. Moon, Y.-S. Kim, E.-C. Lee, Y.-G. Jin and K. J. Chang, Phys. Rev. B: Condens. Matter Mater. Phys., 2002, 65, 1-4.

20 W. M. Silva, H. Ribeiro, L. M. Seara, H. D. R. Calado, A. S. Ferlauto, R. M. Paniago, C. F. Leite and G. G. Silva, J. Braz. Chem. Soc., 2012, 23, 1078-1086.

21 W. M. Silva, H. Ribeiro, J. C. Neves, H. D. R. Calado, F. G. Garcia and G. G. Silva, J. Therm. Anal. Calorim., 2014, 115, 1021-1027.

22 M. A. Hamon, K. L. Stensaas, M. A. Sugar, K. C. Tumminello and A. K. Allred, Chem. Phys. Lett., 2007, 447, 1-4.

23 H. Terrones and M. Terrones, New J. Phys., 2003, 5, 1-37.

24 M. Yudasaka, S. Iijima and V. H. Crespi, Top. Appl. Phys., 2008, 111, 605-629.

25 H. F. Dos Santos, L. A. De Souza, W. B. De Almeida and T. Heine, J. Phys. Chem. C, 2014, 118, 24761-24768.

26 N. Saikia and R. C. Deka, Chem. Phys. Lett., 2010, 500, 65-70.

27 T. Nongnual, S. Nokbin, P. Khongpracha, P. A. Bopp and J. Limtrakul, Carbon, 2010, 48, 1524-1530.

28 I. Kumar, S. Rana and J. W. Cho, Chem.-Eur. J., 2011, 17, 11092-11101.

29 Y. Su, S. Pei, J. Du, W.-B. Liu, C. Liu and H.-M. Cheng, Carbon, 2013, 53, 4-10.

$30 \mathrm{P.} \mathrm{Xu}, \mathrm{J}$. Loomis and B. Panchapakesan, Appl. Phys. Lett., 2012, 100, 1-5.

31 X. Feng, W. Gao, S. Zhou, H. Shi, H. Huang and W. Song, Anal. Chim. Acta, 2013, 805, 36-44.

32 (a) A. M. Da Silva Jr, G. M. A. Junqueira, C. P. A. Anconi and H. F. Dos Santos, J. Phys. Chem. C, 2009, 113, 10070-10084; (b) A. M. Da Silva and H. F. Dos Santos, 2017, to be submitted.

33 M. J. Frisch, G. W. Trucks, H. B. Schlegel, G. E. Scuseria, M. A. Robb, J. R. Cheeseman, G. Scalmani, V. Barone, B. Mennucci, G. A. Petersson, H. Nakatsuji, M. Li, X. Caricato, H. P. Hratchian, A. F. Izmaylov, J. Bloino, G. Zheng, J. L. Sonnenberg, M. Hada, M. Ehara, K. Toyota, R. Fukuda, J. Hasegawa, M. Ishida, T. Nakajima, Y. Honda, O. Kitao, H. Nakai, T. Vreven, J. A. Montgomery Jr, J. E. Peralta, F. Ogliaro, M. Bearpark, J. J. Heyd, E. Brothers, K. N. Kudin, V. N. Staroverov, R. Kobayashi, J. Normand, K. Raghavachari, A. Rendell, J. C. Burant, S. S. Iyengar, J. Tomasi, M. Cossi, N. Rega, J. M. Millam, M. Klene, J. E. Knox, J. B. Cross, V. Bakken, C. Adamo, J. Jaramillo, R. Gomperts, R. E. Stratmann, O. Yazyev, A. J. Austin, R. Cammi, C. Pomelli, J. W. Ochterski, R. L. Martin, K. Morokuma, V. G. Zakrzewski, G. A. Voth, P. Salvador, J. J. Dannenberg, S. Dapprich, A. D. Daniels, Ö. Farkas, J. B. Foresman, J. V. Ortiz, J. Cioslowski and D. J. Fox, Gaussian, Inc., Wallingford CT, 2009.

34 R. G. Parr and W. Yang, Density-Functional Theory of Atoms and Molecules, Oxford University Press, Oxford, 1989.

35 C. Lee, W. Yang and R. G. Parr, Phys. Rev. B: Condens. Matter Mater. Phys., 1988, 37, 785-789.

36 W. J. Hehre, L. Radom, P. V. R. Schleyer and J. A. Pople, $A b$ initio Molecular Orbital Theory, Wiley, New York, 1986.

37 B. Liu, H. Jiang, A. V. Krasheninnikov, A. G. Nasibulin, W. Ren, C. Liu, E. I. Kauppinen and H.-M. Cheng, Small, 2013, 9, 1379-1386.

38 K. Pramoda, K. Moses, M. Ikram, K. Vasu, A. Govindaraj and C. N. R. Rao, J. Cluster Sci., 2014, 25, 173-188.

39 Y. Zhao and D. G. Truhlar, Theor. Chem. Acc., 2008, 120, 215241. 